\title{
Transient Inhibition of Astrocytogenesis in Developing Mouse Brain Following Postnatal Caffeine Exposure
}

\author{
LUC DESFRERE, PAUL OLIVIER, LESLIE SCHWENDIMANN, CATHERINE VERNEY, AND PIERRE GRESSENS
}

\author{
Inserm, U676 [L.D., O.P., L.S., C.V., P.G.], 75019 Paris, France; IFR02 and IFR25 [L.D., O.P., C.V., P.G.], Faculté de Médecine Denis \\ Diderot, Université Paris 7, 75018 Paris, France; AP HP [L.D.], Service de médecine néonatale de Port-Royal, Groupe Hospitalier \\ Cochin Saint-Vincent-de-Paul and Université Paris 5 René Descartes, 75014 Paris, France; AP HP [P.G.], Service de Neurologie \\ Pédiatrique, Hôpital Robert Debré, 75019 Paris, France
}

\begin{abstract}
Caffeine is frequently administered in human preterm newborns. Although some data suggest a potential risk for the developing brain, its impact has not been fully evaluated. We used a murine model of postnatal caffeine treatment in which mouse pups received intraperitoneal injections of caffeine from postnatal days 3 to 10. Caffeine exposure resulted in a transient reduction of glial fibrillary acidic protein and $\mathrm{S} 100 \beta$ protein expression in various brain areas during the first 2 postnatal weeks $(19.8 \%$ and $23.2 \%$ reduction in the hippocampus at $\mathrm{P} 15$, respectively). This effect was dose-dependent and at least partly involved a reduction of glial proliferation, as a caffeine-induced decrease of 5-bromodeoxyuridine incorporation was observed in the dentate gyrus and subventricular zone $(25.8 \%$ and $26.6 \%$, respectively) and no increase of programmed cell death (cleaved caspase- 3 immunostaining) was observed at postnatal day 7. This effect could be reproduced with an antagonist of $\mathrm{A}_{2 \mathrm{a}}$ adenosine receptor $\left(\mathrm{A}_{2 \mathrm{a}} \mathrm{R}\right)$ and was blocked by co-injection of an agonist. These results suggest that postnatal caffeine treatment might induce an alteration of astrocytogenesis via $\mathrm{A}_{2 \mathrm{a}} \mathrm{R}$ blockade during brain development. Although no obvious neuritic abnormalities (microtubule-associated protein 2 and synaptophysin immunostaining) were observed, postnatal caffeine treatment could have long-term consequences on brain function. (Pediatr Res 62: 604-609, 2007)
\end{abstract}

$\mathrm{M}$ any newborns are exposed to caffeine (1,3,7-trimethylxanthine) during the perinatal period, as caffeine has been used for more than $35 \mathrm{y}$ to reduce the frequency of apnea in preterm infants (1). Also, it is the most popular psychoactive drug, commonly ingested in various beverages such as coffee and tea (2). During pregnancy, the half-life of caffeine is tripled (3) and it readily crosses the placenta and bloodbrain barrier. Caffeine is concentrated in the fetal brain, at least in animal models (4).

A wealth of evidence derived from animal studies indicates that caffeine exposure may have neurotoxic side effects. Caffeine accelerates telencephalic vesicle evagination by regulating death and proliferation rate in early postimplantation mouse embryos (5). It causes a proportionally greater loss of brain weight than body weight with a decrease of both constitutive material such as DNA, RNA, cholesterol, and pro-

Received April 17, 2007; accepted June 22, 2007.

Correspondence: Luc Desfrere, M.D. Service de Médecine Néonatale de Port-Royal 123 Boulevard de Port Royal 75014 Paris, France Tel: 331584121 51, Fax: 33158 412160 Email: luc.desfrere@cch.ap-hop-paris.fr

This study was supported by Inserm and Université Paris 7 teins (2), and functional material such as neurotransmitters and ions (6). In vitro, caffeine has been shown to induce apoptotic neuronal death (7) and inhibit cholesterol synthesis by glial cells (8). It is able to decrease the number of proliferating glial cells, and affects the composition of the extracellular matrix, which could impair myelination (9). However, most of these neurotoxic side effects were observed with concentrations higher than those observed during human caffeine consumption or treatment. In low micromolar ranges, it is well established that caffeine probably exerts many of its biologic effects by acting as an antagonist of $A_{1}$ and $A_{2 a}$ adenosine receptors $\left(A_{1} R\right.$ and $A_{2 a} R$, respectively) (10).

The present study was designed to examine the influence of low doses of caffeine on the developing mouse brain at ages corresponding to the neurodevelopmental stage of human infants who are given caffeine in neonatal intensive care units (11). Our results show that following caffeine treatment, some disturbances of astrogliogenesis are visualized by immunohistochemistry in the developing mouse brain probably mediated via $\mathrm{A}_{2 \mathrm{a}} \mathrm{R}$.

\section{METHODS}

Animals and experimental design. Experimental protocols were approved by the institutional review committee, meet the INSERM guidelines, and were carried out in accordance with the Guide for the Care and use of Laboratory Animals as adopted and promulgated by the U.S. National Institutes of Health. All animals were kept in a ventilated room under controlled conditions of lighting (12-h light/dark cycle) and temperature $\left(22^{\circ} \mathrm{C} \pm 2\right)$ and were given free access to food and water. The day of birth was considered as postnatal day (P) 0. At P3, pups from each litter were assigned to receive intraperitoneal injections $(5 \mu \mathrm{L})$ of caffeine (caffeine citrate, Cooper, Melun, France) or vehicle ( $0.9 \%$ sodium chloride) from P3 to P10. The schedule of caffeine treatment comprised a loading dose at P3 (10 mg/kg caffeine base) following by subsequent doses of $2.5 \mathrm{mg} / \mathrm{kg}$ once daily from P4 to P10. The pups were randomly killed under anesthesia with isoflurane at P7, P10, P15, P20 ( $n=10$ /group $)$ and P40 $(n=8 /$ group $)$. Body and brain weights were recorded on the day of sacrifice.

For short-term proliferation assays, other animals were co-injected at $\mathrm{P} 7$ with 5 -bromodeoxyuridine $(\mathrm{BrdU})(50 \mathrm{mg} / \mathrm{kg})$. Each anesthetized animal $(n=10 /$ group) was killed $8 \mathrm{~h}$ later and received a transcardial infusion of $4 \%$ paraformaldehyde (0.12 M, pH 7.4).

For the dose-response study, the effects of one of the 4 loading doses of caffeine at P3 $(5,10,20,40 \mathrm{mg} / \mathrm{kg})$ following by subsequent doses of $25 \%$ of the loading dose from P4 to P10 (10 mice/group) were studied at P15.

Abbreviations: $\mathbf{A}_{\mathbf{1}} \mathbf{R}, \mathrm{A}_{1}$ adenosine receptor; $\mathbf{A}_{\mathbf{2}} \mathbf{R}, \mathrm{A}_{2 \mathrm{a}}$ adenosine receptor; BrdU, 5-bromodeoxyuridine; GFAP, glial fibrillary acidic protein; IR, immunoreactive; MAP2, microtubule-associated protein 2; P, postnatal day; S100, $\mathrm{S} 100 \beta$ protein 
To determine the mechanism of caffeine effect, other pups (10 mice/group) received daily injections of selective $A_{1} R$ and $A_{2 a} R$ antagonists (1,3-dipropyl8-cyclopentylxanthine (DPCPX; $5 \mathrm{mg} / \mathrm{kg} / \mathrm{d}$ ) and 7-(2-phenylethyl)-5-amino2-(2-furyl)-pyrazolo-[4,3-e]-1,2,4-triazolo[1,5-c] pyrimidine (SCH 58261; 5 $\mathrm{mg} / \mathrm{kg} / \mathrm{d})$, respectively) or a selective $A_{1} R$ or $A_{2 a} R$ agonists $\left(N^{6}\right.$ cyclopentyladenosine (CPA; $1 \mathrm{mg} / \mathrm{kg} / \mathrm{d}$ ) and 2-p-(2-carboxyethyl)phenethylamino-5'-N-ethylcarboxamido-adenosine hydrochloride (CGS 21680; $5 \mathrm{mg}$ / $\mathrm{kg} / \mathrm{d}$ ), respectively) which were administered alone or in combination with caffeine from P3 to P10. These doses have been previously reported to mimic the caffeine effects $(12,13)$. All these drugs were dissolved in $25 \%$ DMSO and were purchased from Sigma Chemical Co. (St. Louis, MO). In this experiment, the control group received daily injections of the vehicle (25\% DMSO).

Immunohistochemistry. After sacrifice the brain was removed and fixed in $4 \%$ formaldehyde for $5 \mathrm{~d}$ at room temperature. After paraffin embedding, 16 $\mu \mathrm{m}$ serial sections (10 $\mu \mathrm{m}$ for BrdU labeling) were cut coronally throughout each whole brain. Three comparable anatomical levels of sections (anterior, median and posterior) were chosen from treated and control groups for immunohistochemistry ( 0.62 to $-0.1,-1.34$ to -2.06 and -2.8 to -3.52 from Bregma in the Paxinos atlas (14)). Deparaffinized sections were incubated overnight at room temperature with mouse MAb directed against microtubule-associated protein type 2 (MAP2) (Sigma Chemical Co., St. Louis, MO; 1:500), synaptophysin (Sigma Chemical Co., St. Louis, MO; 1:200) or rabbit polyclonal antibodies directed against glial fibrillary acidic protein (GFAP) (Dako, Glostrup, Denmark; 1:500), S100 $\beta$ protein (S100) (Swant, Bellinoza, Switzerland; 1:1000) or cleaved caspase-3 (Cell Signaling Technology, Danvers, MA; 1:200). Labeled antigens were detected using avidin-biotin peroxidase kits (Vector, Burlingame, C.A.) according to the manufacturer's instructions, with diaminobenzidine (Sigma Chemical Co.) as chromogen and $\mathrm{H}_{2} \mathrm{O}_{2}$ as substrate. Sections from control and treated-animals were treated simultaneously to avoid regional and experimental variations in labeling intensity. As control, representative sections were processed in the same way omitting primary antibodies in the incubation process. Under these conditions, no specific immunostaining was observed (data not shown). For BrdUimmunostaining, a pretreatment with $0.2 \%$ trypsin pretreatment (Sigma Chemical Co.) for $15 \mathrm{~min}$ at $37^{\circ} \mathrm{C}$, DNA denaturation step in $2 \mathrm{~N} \mathrm{HCL}$ for 30 $\mathrm{min}$ at room temperature, and two 30-min washes in $0.1 \mathrm{M}$ lysine was performed before incubation with a rat MAb (Biotechnology, Oxfordshire, UK; 1:100). BrdU-immunoreactive (IR) cells were visualized with a secondary antibody coupled to the green fluorescent marker Fluoroprobe S488 (Interchim, Montluçon, France).

Qualitative and quantitative analysis of histologic data. Since $A_{1} R$ are ubiquitous within the CNS, with high levels expressed in the cerebral cortex, hippocampus, thalamus and as $\mathrm{A}_{2 \mathrm{a}} \mathrm{R}$ are particularly abundant in the striatum, we performed quantification of GFAP and S100-IR cells in these brain areas: motor, somatosensory and visual areas of the upper layers of the cortex, white matter in the corpus callosum at the level of the cingulum, lacunosummoleculare of CA1 region in the whole rostral-caudal extent of the dorsal hippocampus (anterior and posterior), striatum and mediodorsal areas of the thalamus. In each area, at least three nonadjacent fields in a section included within a square-grid reticule were examined at $\times 400$ magnification $(0.065$ $\mathrm{mm}^{2}$ ). Averages of 4 nonadjacent sections per pup were used to determine the number of BrdU-IR cells within the dentate gyrus (including its hilus) and subventricular zone. Semiqualitative analysis of MAP2 or synaptophysin staining was focused on the neocortex and striatum, respectively. Based on the analysis of pairs of sections including similar anatomical regions from controls and caffeine-treated groups, only obvious differences of cytoarchitecture and of staining between the two experimental groups were considered as significant. Cleaved caspase-3-IR cells were quantified in the whole neocortex, hippocampus and striatum at P7, P10 and P40. All quantitative measurements were performed by observers blinded to the animal's experimental group.

Statistical analysis. Quantitative results were expressed as means \pm SEM. Statistical analysis of histologic data were performed using one or two-way ANOVA with a multiple comparisons posttest, or a $t$ test, as appropriate (GraphPad (4) Prism version for Windows; GraphPad Software, San Diego, CA).

\section{RESULTS}

Mortality, behavioral signs, and postnatal growth. Caffeine treatment did not modify postnatal mortality regardless of the doses used (postnatal mortality less than 3\% for live newborn pups) and no behavioral changes (muscle tone, posture, activity-sleep alternation and duration, and suckling behavior) were observed. No differences in body and brain weight gains were observed between the treated and untreated groups (data not shown).

Caffeine treatment decrease the astrocytic density (GFAP and S100-labeled cells). Caffeine treatment induced a transient decrease of GFAP-IR cells at P7, P10 and P15 in the various areas studied, except in the thalamus (Fig. $1 A-C$ ), but the between-group difference was no longer observed at P20 and P40 (Fig. $1 D$ and $E$ ). The maximum effect of treatment was observed at P15 (Fig. 1 C). Partial comparisons for each postnatal age showed that caffeine-treated pups had significantly lower GFAP-IR cell densities at P15 with a mean reduction of $42.5 \%$ and $19.8 \%(p<0.001)$ in the striatum and lacunosum-moleculare of CA1, respectively, whereas the 2 groups were not significantly different at P20 and P40. This decrease of GFAP-IR cells in the caffeine group was not associated with obvious changes of the morphologic appearance of astrocytes (Fig. $2 B, C, E$ and $F$ ). To confirm a real decrease of astrocytic cell bodies and not simply a decrease of GFAP immunoreactivity, the density of another glial marker, S100, was also investigated at P15 (Fig. $3 A-D$ ). Caffeine also induced a decrease of S100-IR cell densities (Fig. 3 E) by $39.5 \%(p<0.001)$ and $23.2 \%(p<0.01)$ in the striatum and hippocampus, respectively, in a similar range to that observed with GFAP immunostaining (Fig. $1 C$ ).

The effect of caffeine treatment on GFAP and S100-IR cell densities is dose-dependent. The increase of caffeine doses resulted in a gradual reduction of the GFAP-IR cell densities in the lacunosum-moleculare of CA1 region at P15 (Fig. $4 A$ and $B$ ). Although only a trend toward a decrease of GFAP-IR cell density was observed at the lowest dose used ( $8.4 \%$ reduction, $\mathrm{ns}$ ), the effect of caffeine was statistically significant at higher doses with a $20.8 \%, 31.0 \%$ and $37.8 \%$ decreases for the $2.5,5$ and $10 \mathrm{mg} / \mathrm{kg}$ doses, respectively $(p<$ $0.01)$. These results obtained following GFAP labeling were confirmed following S100 labeling (Fig. $4 C$ and $D$ ). The density of S100-IR cells was reduced by $20.5 \%, 28.1 \%$ and $33.8 \%$ for the $2.5,5$ and $10 \mathrm{mg} / \mathrm{kg}$ doses respectively, in caffeine-treated animals versus controls $(p<0.01)$.

Caffeine treatment induced a reduction of postnatal cell proliferation. To further analyze the caffeine-induced reduction of astrocytic density, control and caffeine-treated groups were injected with BrdU at P7 and killed $8 \mathrm{~h}$ later. The densities of BrdU-labeled nuclei in the subventricular zone and dentate gyrus, two areas of postnatal proliferation, were decreased by $26.6 \%$ and $25.8 \%$ in animals treated by caffeine compared with controls $(p<0.01)$ (Fig. 5).

No significant effect of caffeine treatment on physiologic apoptotic cell death. Immunostaining with cleaved caspase-3 antibody was performed to investigate the possible effect of caffeine treatment on physiologic neuronal cell death. A few cleaved caspase-3-IR cells were observed in the different layers of the cerebral cortex, white matter, hippocampus, and striatum in both caffeine-treated and control mice (Fig. 6). A peak of cell death was observed at P7 in the different brain areas studied and rare labeled cells were detected at P10 and P40. The mean numbers of cleaved caspase-3-IR cells in each area were not significantly different at P7 between the caffeine-treated and control groups. 

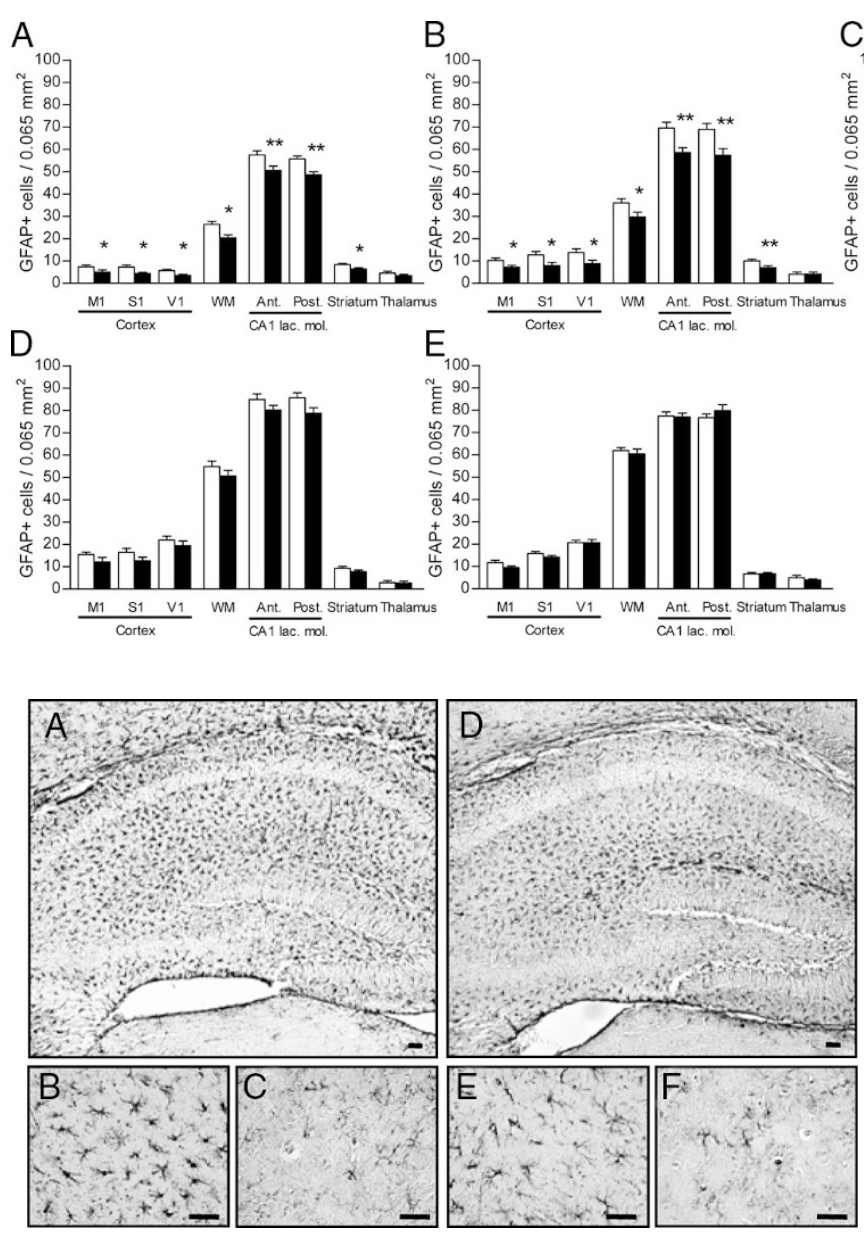

Figure 2. Caffeine decreases GFAP-IR cell densities at P15. GFAPimmunoreactivity at the level of hippocampus $(A, B, D$, and $E)$ and striatum $(C$ and $F$ ). $B$ and $E$ : high magnification at the level of lacunosum-moleculare of CA1 region of the hippocampus. Note the obvious reduction of GFAP-IR cells in the caffeine-treated mouse $v s$ control in the hippocampus $(D-E v s$ $A-B)$ and in the striatum $(F v s C)$. Bar $=20 \mu \mathrm{m}$.

Probable involvement of $A_{2 a}$ adenosine receptors. The effects of selective adenosine receptor agonists or antagonists were investigated at P15 to determine whether the reduction of GFAP observed in caffeine-treated mice was mediated by adenosine receptors. Treatment by a selective $A_{1} R$ agonist (CPA) or antagonist (DPCPX) did not induce any modification of GFAP-IR cell densities (Fig. $7 A-C$ ). In contrast, treatment by $\mathrm{SCH} 58261$, a selective $\mathrm{A}_{2 \mathrm{a}} \mathrm{R}$ antagonist, mimicked the caffeine-induced reduction of GFAP expression in the striatum and hippocampus $(6.3 \pm 0.7$ versus $8.5 \pm 0.5$ and $47.0 \pm 2.5$ versus $50.0 \pm 1.7$ in the $\mathrm{SCH} 58261$ versus caffeine groups, respectively; NS). Furthermore, whereas cotreatment by CPA did not change the effect of caffeine, CGS 21680 inhibited the caffeine-induced reduction of GFAP-IR cell densities in the striatum and hippocampus (13.7 \pm 1 versus $8.5 \pm 0.5(p<0.01)$ and $63.5 \pm 3.3$ versus $50.0 \pm 1.7$ $(p<0.05)$ in the CGS $21680+$ caffeine versus caffeine groups, respectively). Collectively, these data suggest that the caffeine-induced reduction of GFAP-IR cell density in the CA1 region is related to the $A_{2 a} R$ antagonist property of caffeine.
Figure 1. Caffeine decreases GFAP-IR cell densities. Quantitative analysis of the number of GFAP-IR cells in the motor (M1), somatosensory (S1) and visual (V1) cortex, white matter (WM), lacunosummolecular of CA1 region (CA1 lac. mol.) of hippocampus, striatum and thalamus from control $(\square)$ and caffeine ( $\square$ ) treated mice at P7 (A), P10 (B), P15 (C), P20 (D) $(n=10 /$ group $)$ and $\mathrm{P} 40(E)(n=8) . \dagger p<$ $0.001, * * p<0.01, * p<0.05$ in a $t$ test. The effect of treatment (all ages combined) and the transient nature of the effect were confirmed by two-way ANOVA, which showed a significant difference between control and caffeine groups $(p<0.001)$ and a significant age interaction with the drug $(p<0.05)$.
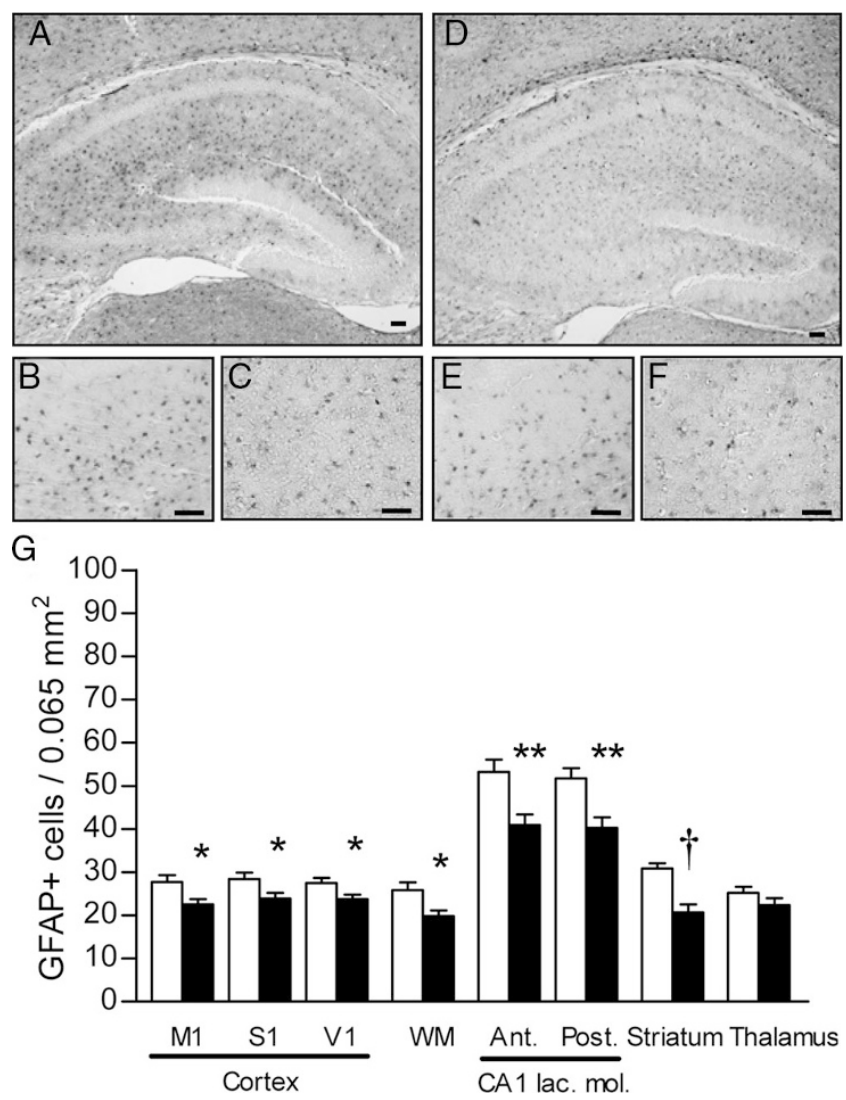

Figure 3. Caffeine decreases S100-IR cell densities at P15. S100immunoreactivity at the level of hippocampus $(A, B, D$, and $E)$ and striatum $(C$ and $F) . B$ and $E$ : high magnification at the level of lacunosummoleculare of CA1 region of the hippocampus. Note the obvious reduction of S100-IR cells in the caffeine treated mouse $v s$ control in the hippocampus $(D-E$ vs $A-B)$ and in the striatum $(F v s C)$. Bar $=20 \mu \mathrm{m} .(G)$ Quantitative analysis of the number of S100-IR cells in the same regions of the motor (M1), somatosensory (S1) and visual (V1) cortex, white matter (WM), lacunosum-molecular of CA1 region (CA1 lac. mol.) of hippocampus, striatum and thalamus from control $(\square)$ and caffeine (ם) treated mice at P15 ( $n=10$ /group). $\dagger p<0.001, * * p<0.01, * p<0.05$ in a $t$ test.

Effect of caffeine on neuritogenesis (MAP2) and synaptogenesis (synaptophysin). No significant difference of MAP2 and synaptophysin staining was observed between the control and caffeine groups at each postnatal age in the neocortex and 
A
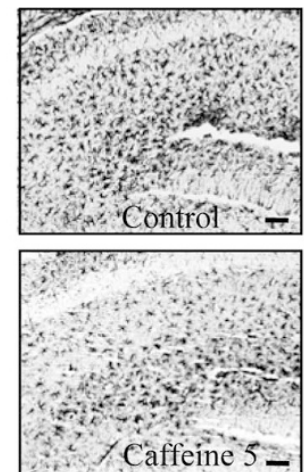

C
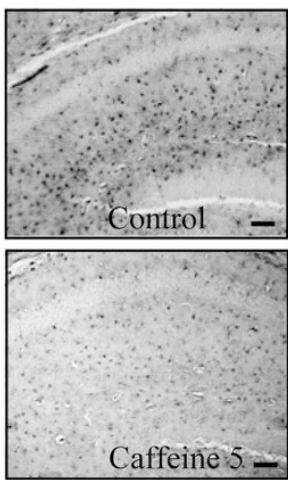
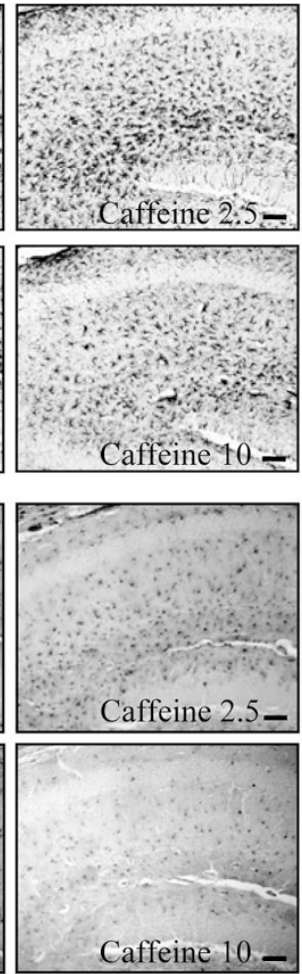

B

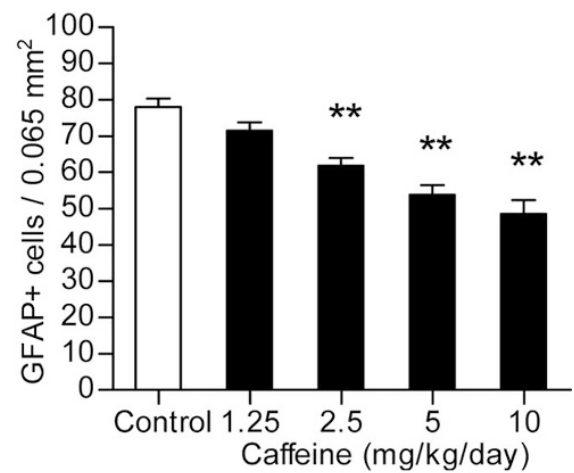

D

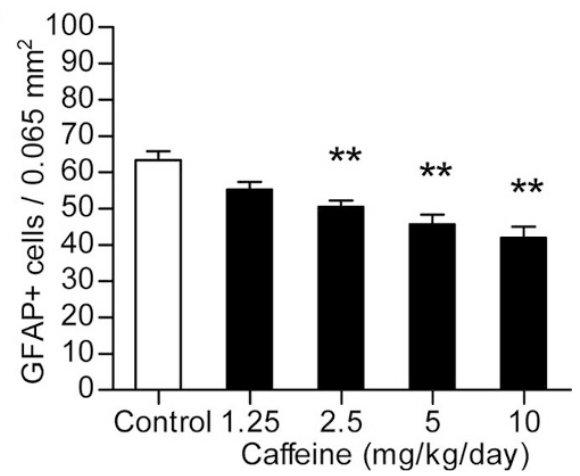

Figure 4. Gradual doses of caffeine induce a gradual decrease of densities of GFAP and S100-IR cell. Representative coronal sections of GFAP $(A)$ and S100-IR cells $(C)$ at the level of lacunosummoleculare of the hippocampus from controls and mice treated with $2.5,5$ or 10 $\mathrm{mg} / \mathrm{kg} / \mathrm{d}$ of caffeine. Bar $=20 \mu \mathrm{m}$. Quantitative analysis of GFAP $(B)$ and S100-IR cells $(D)$ in lacunosum-moleculare of CA1 region of the anterior hippocampus at P15. ** $p<0.01$ in a one-way ANOVA with Dunnett's multiple comparisons posttest (caffeine groups vs controls).

Figure 5. Caffeine induces a decrease of cell proliferation at $\mathrm{P} 7$. Coronal sections of BrdU-IR cells from controls $(A$ and $B$ ) and caffeine-treated pups ( $C$ and D) in the subventricular zone $(A$ and $C$ ) and the dentate gyrus of hippocampus ( $B$ and $D)$. (E) Quantitative analysis of the number of BrdU-IR cells in the subventricular zone and the dentate gyrus at P7 $(n=10 /$ group). LV: lateral ventricle. $\square$ : control; 口: caffeine. $*^{*} p<0.01$ in a $t$ test.
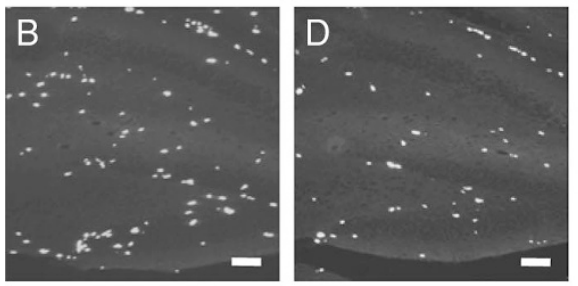

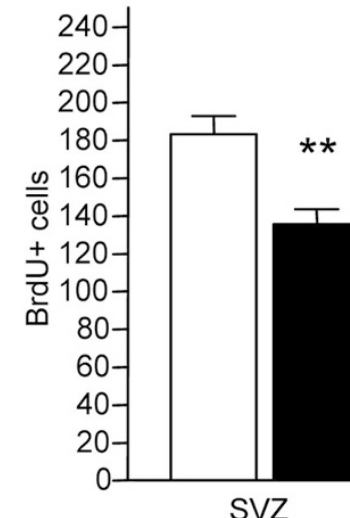

SVZ

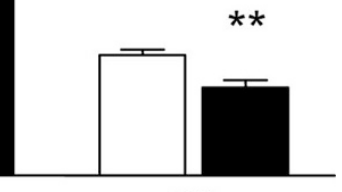

DG striatum, respectively. Semiqualitative analysis confirmed the similar staining intensity for these 2 markers (data not shown).

\section{DISCUSSION}

The main finding of this study is that postnatal caffeine exposure induces a transient and dose-dependent reduction of GFAP expression, a marker of the astrocytic population. It has been shown that astrocytes have two different origins during brain development. One population arises from transforming radial glial cells and the other forms from precursors migrating from the subventricular zone after completion of neuron division and migration (15). Unlike neurons, astrocyte proliferation and maturation with increased GFAP expression occur during the first 2 wk after birth in rodents, which corresponds to the time of caffeine exposure in our model (16). The decrease of GFAP expression observed in this study might therefore represent a reduction of either astrocytic prolifera- tion and/or maturation. The decrease of S100 expression, another marker of astrocytes, suggested that the caffeine effect at least partly involves a reduction of the proliferation rate. The decrease of BrdU incorporation in caffeine-treated pups is in agreement with this hypothesis. An alternate explanation could be a caffeine-induced increase of astrocytic cell death as caffeine has been recently shown to cause caspase-3dependent neuronal cell apoptosis in vitro and in vivo (7). However, in the present model, the similar cleaved caspase3 -immunostaining in the control and caffeine groups was not in favor of this hypothesis.

The caffeine-induced decrease of astrocytic population observed in this study appears moderate and transient. Normalization of astrocytic densities during the first few postnatal weeks has been previously reported in other animal models of astrocytogenesis inhibition $(17,18)$. The astrocytes that have reached their final destination maintain their capacity to pro- 


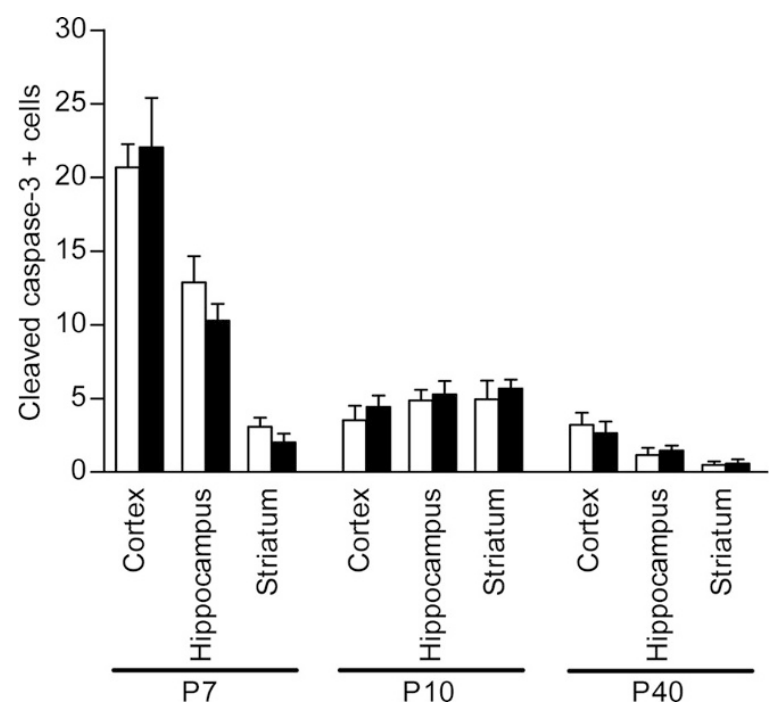

Figure 6. Effects of caffeine treatment on physiologic apoptotic cell death at P7. Quantitative analysis of the number of cleaved caspase-3-IR cells in the neocortex, hippocampus and striatum from controls $(\square)$ and caffeine ( $\square$ ) treated mice at P7, P15 ( $n=10$ /group) and P40 $(n=8)$. No differences were observed.

liferate throughout adult life; this protracted in situ proliferation very likely accounts for the normalization of the astrocytic population in adults. The long-term consequences of this transient alteration of astrocytogenesis on brain function remain to be clarified. However, it could induce disturbances of neuronal circuitry and functioning, as astrocytes carry out many functions during brain development. They support neuronal function and neuronal plasticity (19), maintain homeostasis in the extracellular fluid, and release a number of neurotransmitters or neurotrophic factors $(20,21)$ and a number of neuritic abnormalities have been reported after transient alteration of astrocyte genesis or depletion by genetic manip- ulation $(18,22)$. Although no obvious alterations of MAP2 and synaptophysin immunostaining were observed, further studies are required to evaluate the potential neuronal consequences in our model and behavioral studies must be conducted to determine the long-term consequences of this early inhibition of astrocytic proliferation and maturation.

Although the effects of adenosine are mediated via four G-protein-coupled receptor subtypes (for a review, see (10)), only $A_{1} R$ and $A_{2 a} R$ are susceptible to activation at the low adenosine concentrations observed under basal conditions and are therefore the likely targets of caffeine. In our animal model, the caffeine-induced reduction of GFAP-IR cell densities appeared to involve $A_{2 a} R$ blockade, as the caffeine effect was mimicked by an $\mathrm{A}_{2 \mathrm{a}} \mathrm{R}$ antagonist and inhibited by an $\mathrm{A}_{2 \mathrm{a}} \mathrm{R}$ agonist. The higher percentage of astrocytic depletion within the striatum, an area with the highest levels of $\mathrm{A}_{2 \mathrm{a}} \mathrm{R}$ (23), also suggested the involvement of these receptors.

Astrocytes in primary culture have been shown to express $A_{2 a} R$ (24). Whereas both $A_{1} R$ and $A_{2 a} R$ are present at birth in rats $(25,26)$, some data suggest the absence of functional $A_{1} R$ and an increased relative importance of $A_{2 \mathrm{a}} \mathrm{R}$ in the immature brain. For example, stimulation of $A_{1} R$ protects the adult brain from ischemic injury (27) but seems to play a minor role in the immature brain (28). $\mathrm{A}_{2 \mathrm{a}} \mathrm{R}$ are also present in the cerebral cortex and hippocampus (29) and play a fundamental role in the viability of cortical tissue during ischemia (28).

In addition to its ability to control CNS functions, extracellular adenosine can also act as a trophic factor with a potential to regulate the proliferation and apoptosis of glial cells. However, data from in vitro studies are controversial. It has been reported that adenosine reduces (30) or increases astrocytic proliferation $(31,32)$ by acting on $A_{1} R$ or $A_{2} R$, respectively. This indicates that multiple purinoceptor subtypes are present
A
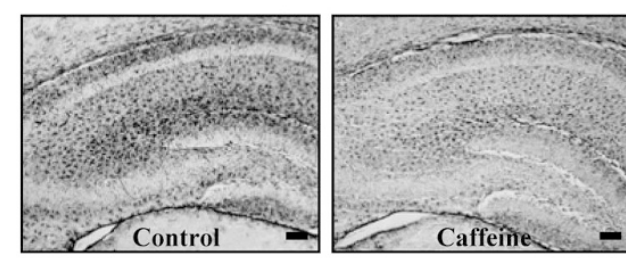

B

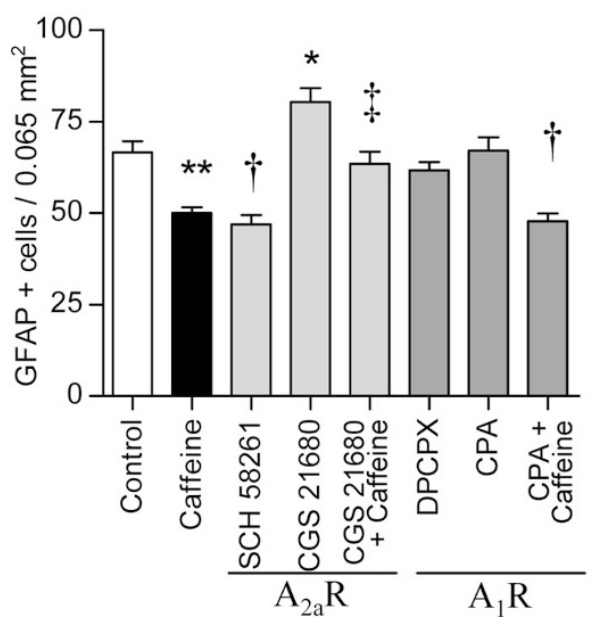

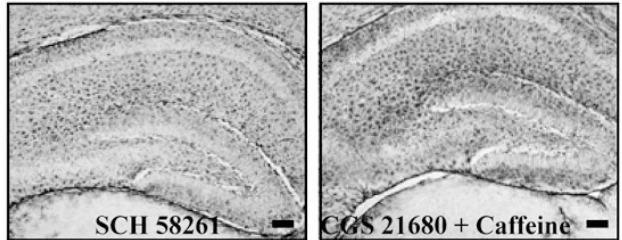

C

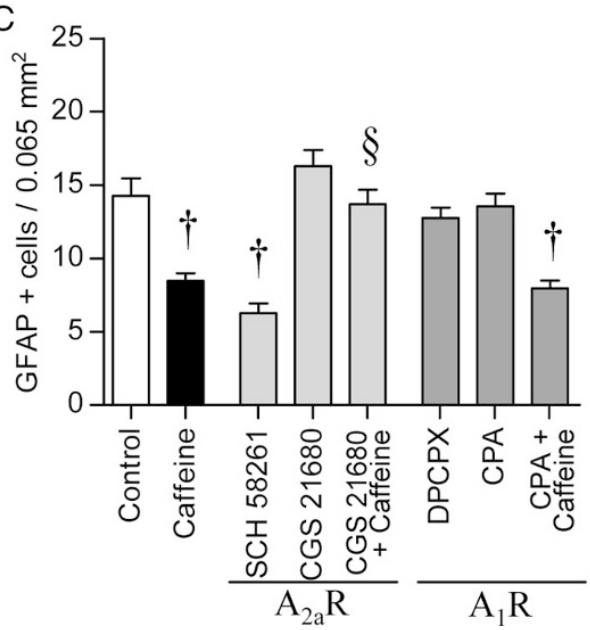

Figure 7. The caffeine-induced reduction of GFAP-IR cell densities seems to be mediated by $\mathrm{A}_{2 \mathrm{a}}$ adenosine receptors. (A) GFAP-IR cells in medial coronal levels of hippocampus at $\mathrm{P} 15$ from control, caffeine, SCH 58261, and CGS $21680+$ caffeine exposed animals. Note that the caffeineinduced reduction of immunoreactivity is mimicked by the selective antagonist of $\mathrm{A}_{2 \mathrm{a}} \mathrm{R}$ (SCH 58261) and inhibited by a selective agonist of $A_{2 a} R$ (CGS 21680). ( $B$ and $C$ ) Quantitative analysis of GFAP-IR cell densities in lacunosum-molecular of CA1 region of the hippocampus $(B)$ and striatum $(C)$ at $\mathrm{P} 15$ from animals treated between P3 and P10 by caffeine, DPCPX or SCH 58261 and CPA or CGS 21680 administered alone or in combination with caffeine ( $n=10$ /group). Control $=$ DMSO 25\%. ${ }^{*} p<0.05,{ }^{* *} p<0.01$ and $\dagger p<$ 0.001 vs controls; $\ddagger p<0.05$ and $\S p<$ 0.01 vs caffeine group in a one-way ANOVA with Bonferroni's multiple comparisons posttest. 
on glial cells and participate in a complex regulation of cell growth. Moreover, adenosine promotes the stellation of astrocytes (33) and the injection of an adenosine analog into rat brain increased the GFAP immunostaining, an effect that was reduced by co-infusion of an $\mathrm{A}_{2} \mathrm{R}$ antagonist (34). It could act as a trophic agent in several ways: directly by inducing functional changes in glial cells, by stimulating the production of trophic factors by glial cells and neurons or indirectly by enhancing the effects of trophic substances on glial cells, as it has been shown that exposure of astrocytes to the selective $\mathrm{A}_{2 \mathrm{a}} \mathrm{R}$ antagonist resulted in concentration-dependent abolition of bFGF induction of astrogliosis (24). Another effect of caffeine is a decrease of cerebral blood flow. Although we cannot rule out this mechanism in our model, it appears unlikely as brain damage caused by hypoxia or ischemia induces astrocyte proliferation.

Methylxanthines, particularly caffeine as the drug of choice, are widely used therapeutically in the treatment of apneic episodes in premature infants (35). During such treatment, premature infants may be exposed to relatively high serum concentrations of caffeine $(5-15 \mathrm{mg} / \mathrm{L})$ for extended periods of time (up to $8 \mathrm{wk}$ ). Although extrapolating from animal models to human clinical medicine should be viewed with caution, the goal of the present study was to use an animal model to mimic clinical exposure to caffeine in premature neonates. The protocol used in this study represented the doses generally used in preterm newborns and P3-P10 mouse pups probably mimic the development stage of the human brain between 24 to 38 wk of gestational age. The alteration of astrocytogenesis observed in the present study after neonatal caffeine exposure provides further experimental data to support that caffeine exposure might have neurologic consequences in preterm infants. Indeed, cognitive impairment, attention deficits and behavioral problems observed in some very preterm infants in the absence of destructive lesions such as periventricular leukomalacia or intraventricular hemorrhage could partly result from exposure of the immature developing brain to noxious factors. Although caffeine therapy has been shown to be beneficial at short-term with a reduction of the rate of bronchopulmonary dysplasia in preterm infants (1), it should not be regarded as completely safe until controlled clinical studies have shown the absence of long-term neurologic sequelae.

In conclusion, in our animal model of postnatal treatment, caffeine induced a decrease of astrocytic densities in various brain areas during the first $2 \mathrm{wk}$ of life, which seemed to involve the $\mathrm{A}_{2 \mathrm{a}} \mathrm{R}$. Many aspects of development depend on proper sequencing so that alteration of one step in the sequence may have far-reaching implications. These results underline the need for the assessment of the long-term neurodevelopmental consequences of caffeine in human neonates to clarify the benefit/risk of this treatment.

\section{REFERENCES}

1. Schmidt B, Roberts RS, Davis P, Doyle LW, Barrington KJ, Ohlsson A, Solimano A, Tin W 2006 Caffeine therapy for apnea of prematurity. N Engl J Med 354:21122121

2. Nehlig A, Daval JL, Debry G 1992 Caffeine and the central nervous system: mechanisms of action, biochemical, metabolic and psychostimulant effects. Brain Res Brain Res Rev 17:139-170
3. Brazier JL, Ritter J, Berland M, Khenfer D, Faucon G 1983 Pharmacokinetics of caffeine during and after pregnancy. Dev Pharmacol Ther 6:315-322

4. Wilkinson JM, Pollard I 1993 Accumulation of theophylline, theobromine and paraxanthine in the fetal rat brain following a single oral dose of caffeine. Brain Res Dev Brain Res 75:193-199

5. Sahir N, Bahi N, Evrard P, Gressens P 2000 Caffeine induces in vivo premature appearance of telencephalic vesicles. Brain Res Dev Brain Res 121:213-217

6. Concannon JT, Braughler JM, Schechter MD 1983 Pre- and postnatal effects of caffeine on brain biogenic amines, cyclic nucleotides and behavior in developing rats. J Pharmacol Exp Ther 226:673-679

7. Kang SH, Lee YA, Won SJ, Rhee KH, Gwag BJ 2002 Caffeine-induced neuronal death in neonatal rat brain and cortical cell cultures. Neuroreport 13:1945-1950

8. Allan WC, Volpe JJ 1979 Reduction of cholesterol synthesis by methylxanthines in cultured glial cells. Pediatr Res 13:1121-1124

9. Marret S, Delpech B, Girard N, Leroy A, Maingonnat C, Menard JF, Fessard C 1993 Caffeine decreases glial cell number and increases hyaluronan secretion in newborn rat brain cultures. Pediatr Res 34:716-719

10. Fredholm BB, Battig K, Holmen J, Nehlig A, Zvartau EE 1999 Actions of caffeine in the brain with special reference to factors that contribute to its widespread use. Pharmacol Rev 51:83-133

11. Clancy B, Darlington RB, Finlay BL 2001 Translating developmental time across mammalian species. Neuroscience 105:7-17

12. El Yacoubi M, Ledent C, Parmentier M, Costentin J, Vaugeois J 2000 SCH 58261 and ZM 241385 differentially prevent the motor effects of CGS 21680 in mice: evidence for a functional 'atypical' adenosine A(2A) receptor. Eur J Pharmacol 401:63-77

13. Kuzmin A, Johansson B, Gimenez L, Ogren SO, Fredholm BB 2006 Combination of adenosine A1 and A2A receptor blocking agents induces caffeine-like locomotor stimulation in mice. Eur Neuropsychopharmacol 16:129-136

14. Paxinos G, Franklin KB.2004 The mouse Brain in Stereotaxic Coordinates. $2^{\text {nd }}$ edition, Academic press, San Diego, p 67

15. Gressens P, Richelme C, Kadhim HJ, Gadisseux JF, Evrard P 1992 The germinative zone produces the most cortical astrocytes after neuronal migration in the developing mammalian brain. Biol Neonate 61:4-24

16. Parnavelas JG 1999 Glial cell lineages in the rat cerebral cortex. Exp Neurol 156:418-429

17. Gressens P, Muaku SM, Besse L, Nsegbe E, Gallego J, Delpech B, Gaultier C, Evrard P, Ketelslegers JM, Maiter D 1997 Maternal protein restriction early in rat pregnancy alters brain development in the progeny. Brain Res Dev Brain Res 103:21-35

18. Zupan V, Nehlig A, Evrard P, Gressens P 2000 Prenatal blockade of vasoactive intestinal peptide alters cell death and synaptic equipment in the murine neocortex. Pediatr Res 47:53-63

19. Vernadakis A 1996 Glia-neuron intercommunications and synaptic plasticity. Prog Neurobiol 49:185-214

20. Lu B, Yokoyama M, Dreyfus CF, Black IB 1991 NGF gene expression in actively growing brain glia. J Neurosci 11:318-326

21. Murphy SN, Miller RJ 1989 Two distinct quisqualate receptors regulate Ca2+ homeostasis in hippocampal neurons in vitro. Mol Pharmacol 35:671-680

22. Delaney CL, Brenner M, Messing A 1996 Conditional ablation of cerebellar astrocytes in postnatal transgenic mice. J Neurosci 16:6908-6918

23. Jarvis MF, Williams M 1988 Differences in adenosine A-1 and A-2 receptor density revealed by autoradiography in methylxanthine-sensitive and insensitive mice. Pharmacol Biochem Behav 30:707-714

24. Brambilla R, Cottini L, Fumagalli M, Ceruti S, Abbracchio MP 2003 Blockade of A2A adenosine receptors prevents basic fibroblast growth factor-induced reactive astrogliosis in rat striatal primary astrocytes. Glia 43:190-194

25. Weaver DR 1993 A2a adenosine receptor gene expression in developing rat brain. Brain Res Mol Brain Res 20:313-327

26. Weaver DR 1996 A1-adenosine receptor gene expression in fetal rat brain. Brain Res Dev Brain Res 94:205-223

27. Rudolphi KA, Schubert P, Parkinson FE, Fredholm BB 1992 Adenosine and brain ischemia. Cerebrovasc Brain Metab Rev 4:346-369

28. Aden U, Leverin AL, Hagberg H, Fredholm BB 2001 Adenosine A(1) receptor agonism in the immature rat brain and heart. Eur J Pharmacol 426:185-192

29. Lopes LV, Halldner L, Rebola N, Johansson B, Ledent C, Chen JF, Fredholm BB, Cunha RA 2004 Binding of the prototypical adenosine A(2A) receptor agonist CGS 21680 to the cerebral cortex of adenosine $\mathrm{A}(1)$ and $\mathrm{A}(2 \mathrm{~A})$ receptor knockout mice. Br J Pharmacol 141:1006-1014

30. Ciccarelli R, Di Iorio P, Ballerini P, Ambrosini G, Giuliani P, Tiboni GM, Caciagli F 1994 Effects of exogenous ATP and related analogues on the proliferation rate of dissociated primary cultures of rat astrocytes. J Neurosci Res 39:556-566

31. Neary JT, McCarthy M, Kang Y, Zuniga S 1998 Mitogenic signaling from P1 and P2 purinergic receptors to mitogen-activated protein kinase in human fetal astrocyte cultures. Neurosci Lett 242:159-162

32. Rathbone MP, Middlemiss PJ, Kim JK, Gysbers JW, DeForge SP, Smith RW, Hughes DW 1992 Adenosine and its nucleotides stimulate proliferation of chick astrocytes and human astrocytoma cells. Neurosci Res 13:1-17

33. Abe K, Saito H 1998 Adenosine stimulates stellation of cultured rat cortical astrocytes. Brain Res 804:63-71

34. Hindley S, Herman MA, Rathbone MP 1994 Stimulation of reactive astrogliosis in vivo by extracellular adenosine diphosphate or an adenosine A2 receptor agonist J Neurosci Res 38:399-406

35. Comer AM, Perry CM, Figgitt DP 2001 Caffeine citrate: a review of its use in apnoea of prematurity. Paediatr Drugs 3:61-79 